\title{
高分子への気体·蒸気の収着
}

\author{
小谷壽 \\ 京都大学名誉教授 函 603 京都市北区小山西花池町 29
}

\section{Sorption of Gases and Vapors in Polymers}

\author{
Hisashi Odani \\ Institute for Chemical Research, Kyoto University \\ Uji, Kyoto 611, Japan
}

This paper reviews some theories and models which are employed in analysis, interpretation, simulation, and prediction of equilibrium and unsteady-state sorption behavior of gases and vapors in nonporous polymer membranes. Applicability of 2- and 3-parameter adsorption isotherms to treat quantitatively the equilibrium sorption behavior is discussed. Sorption isotherms of organic vapors in a disubstituted polyacetylene, poly[1-(trimethylsilyl)-1-propyne], membrane is quoted. It has been shown that a treatment, which takes account of both adsorption on the internal and external polymer surfaces with lateral penetrant-penetrant interaction and dissolution into the polymer network, reproduces satisfactorily the complex shape of the sorption isotherms. The limitations of the dual-mode sorption model are discussed in light of recent results of spectroscopic measurements of systems of gases and glassy polymers. The analysis and the interpretation of nonsteady-state sorption behavior of gases and vapors in rubbery polymer membranes are discussed in terms of the free volume models developed by Fujita and by Vrentas and Duda.

Key words : sorption/polymer membrane/sorption isotherm/dual-mode sorption model/sorption process / free volume model

\section{1.はじめに}

無孔性（非多孔）高分子膜への気体・蒸気の透 過過程は，まず膜の表面層で気体・蒸気分子の収 着 (吸着と吸収をひとまとめにした学術用語 ${ }^{1)}$, あるいは溶解）が起こり, 次いで収着した分子が 膜中を移動（拡散）することによって進む，すな わち, この溶解一拡散 ${ }^{2)}$ 機構によれば, 平衡的性
質である収着特性と動的な物性である拡散特性 が，透過過程を支配する 2 つの主要因子である. この総説の前半では, 平衡収着量の解析や数量的 表現に用いられている, 種々の収着等温式や二元 収着モデルなどの適用を, 膜科学の立場から述べ る. 後半では, 収着の動的過程, すなわち拡散過 程について, Fick 型過程に限って, 拡散係数の 濃度依存性と, その自由体積モデルによる解析な 


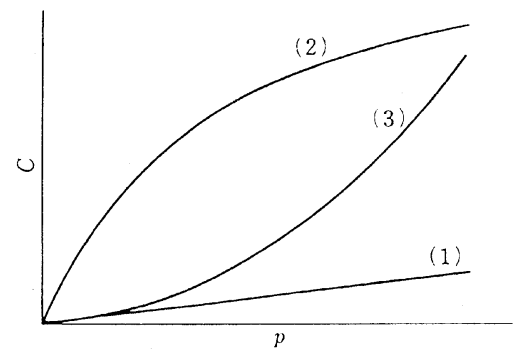

Fig. 1 Typical sorption curves.

どについて述べる.

\section{2. 収着等温線, 収着等温式}

平衡状態において収着している気体・蒸気分子 の, 高分子の単位体積あるいは質量当たりの量 $\mathrm{C}$ と平衡圧 $\mathrm{p}$ との関係を表す収着等温線の基本的 なものを, Fig. 13) に示す. 低分子一高分子系が 熱力学的理想系である場合には, (1)の Henry 型 と呼ばれる直線となる. 低分子と高分子鎖中の基 や高分子固体中の吸着座席との間に強い局所的相 互作用があるときには, 等温線は曲線 (2) の形と なる．高分子と低分子がともに無極性か，あるい は極性があってもそれが弱い場合には，等温線は 一般に曲線 (3) の形になる.

$\mathrm{p}$ が小さい領域で (2) の形の $\mathrm{C}$ 対 $\mathrm{p}$ 関係の定 量的な記述には, 低分子の局在化吸着を考慮した 物理吸着理論により導かれた等温式が用いられて いる ${ }^{3)}$. 2 個のパラメーターをもつ等温式には, Langmuir の式 ${ }^{4)}$, Brunauer, Emmett, Teller の式 $\left(\infty-\mathrm{BET}\right.$ 式 ${ }^{5)}$, Jura, Harkins の 式6), Freundlich の式 ${ }^{7)}$ な゙がある. 3 パラ メーターの等温式には, 吸着が有限な $\mathrm{n}$ 層まで しか起こらないとした $\mathrm{n}$ 層 BET 式 ${ }^{5)}$, Halsey の式 ${ }^{8)}$ などがある。これらの等温式は, 収着等温 線の数量的表現に極めて便利であるが, 吸収が主 現象と考えられる高分子固体中への気体分子の収 着では, 固体表面への吸着と環境が非常に違うこ とを考慮に入れた上での適用, 考察が要求される.

Fig. 1 の (3) の形の等温線は, 低分子と高分 子の無秩序な混合を仮定した, Flory, Huggins
膜 (MEMBRANE), Vol. 21 No. 6 (1996)

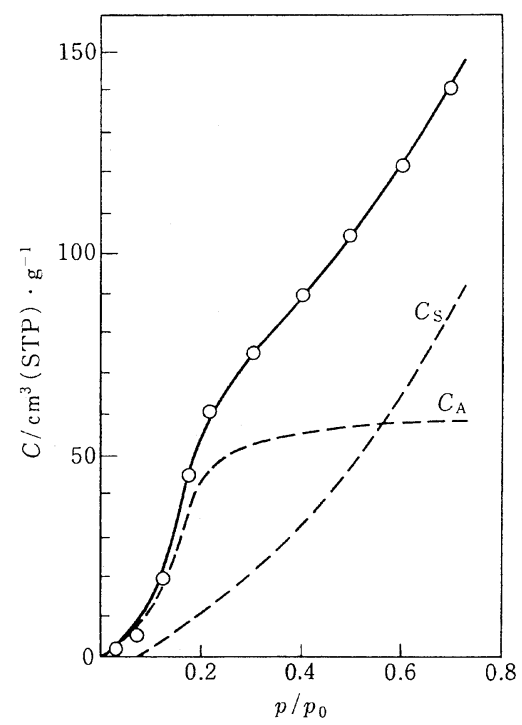

Fig. 2 Calculated sorption isotherm of ethanol vapor in PMSP at $25^{\circ} \mathrm{C}$.

The parameters used are : $\mathrm{C}_{A}{ }^{\prime}=61.8 \mathrm{~cm}^{3}$

(STP) $\mathrm{g}^{-1} ; \mathrm{K}=1.15 ; \mathrm{k}=3.35 ; \mathrm{S}_{0}=75.5 \mathrm{~cm}^{3}$

(STP) $\mathrm{g}^{-1} ; \gamma=0.98 ; \mathrm{p}_{D}=0.08$

Unfilled circles are experimental ${ }^{12)}$.

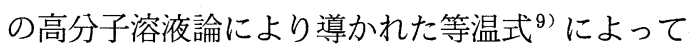
説明される.この式は, Vrentas, Duda の自由 体積モデルによる, 拡散係数およびその濃度依存 性の予測 ${ }^{10)}$ でも使われている.

これまでは単純な形の収着等温線について述べ てきたが, 次に複雑な形の等温線の定量的表現, シ ミュレーションをどのように取り扱えばよいかを 示した一例を挙げる. 二置換ポリアセチレンであ る [1-(trimethylsilyl)-1-propyne)] (PMSP) の膜は, 合成高分子膜のうち最高の気体透過性を 示すものとして非常に有名である ${ }^{11)}$ が, この膜 へのエタノールなどの有機低分子蒸気の収着等温 線は, Fig. 2 ${ }^{12)}$ に測定点を白丸で示したように, 非常に複雑な形をしている.

この複雑な形の等温線は, 以下に示すようにし て数量的に取り扱うことができる. 低分子の収着 量 C は, PMSP 膜の外部表面と, 膜中に多数存 在することが電子顕微鏡観察によって明らかにさ れている, 直径が約 $1 \mu \mathrm{m}$ の円筒形状のボイドの 内部表面への吸着量 $\mathrm{C}_{A}$ と, 高分子網目への溶解 
量 $\mathrm{C}_{s}$ の和として表されるものとする. すなわち

$$
\mathrm{C}=\mathrm{C}_{A}+\mathrm{C}_{S}
$$

低圧領域において主として等温線の形を定める $\mathrm{C}_{A}$ に対しては, Fowler が統計力学を用いて導 いた関係 ${ }^{13)}$

$$
\begin{aligned}
& \mathrm{C}_{A}=\mathrm{C}_{A}{ }^{\prime} \theta, \\
& \mathrm{x}=\theta /[(1-\theta) \mathrm{K}] \cdot \exp (-\mathrm{k} \theta)
\end{aligned}
$$

を用いる.ここで， $\theta$ は単分子層吸着座席が低分 子で覆われている分率, $\mathrm{x}$ は気体圧力 $\mathrm{p}$ とその温 度における飽和蒸気圧 $\mathrm{p}_{0}$ との比, すなわち相対 蒸気圧, $\mathrm{C}_{A}{ }^{\prime}$ と $\mathrm{K}$ は Langmuir 吸着理論の容量 定数および親和力定数に相当するパラメーター, $\mathrm{k}$ は吸着した低分子同士の間の相互作用の測度之 なるパラメーターである.

$\mathrm{C}_{s}$ は, 相対蒸気圧があるしきい值を超えると 高分子網目への低分子の溶解が始まるとすれば

$$
\mathrm{C}_{S}=\mathrm{S}_{0} \exp \left[\gamma\left(\mathrm{x}-\mathrm{x}_{D}\right)\right] \cdot\left(\mathrm{x}-\mathrm{x}_{D}\right), \mathrm{x} \geqq \mathrm{x}_{D}
$$

と表される.ここで， $\mathrm{x}_{D}$ は相対蒸気圧のしきい 值, $\mathrm{S}_{0}, \gamma$ はパラメーターで, 後者は高圧領域で 収着量が急激に増加することを考慮したものであ る. Fig. 2 には $\mathrm{C}_{A}$ および $\mathrm{C}_{S}$ の計算曲線を破線 で，またこれらの和 $\mathrm{C}$ の計算線を実線で描き， 測定点と比べられている. 図説明に示した 6 個の パラメーターを用いて，測定結果は満足に再現さ れている.

複雑な形の収着等温線の数量的表現の 1 例を示 したが，これと類似の取扱いは表面化学などの分 野で過去に多くされてきている.したがってこの ような取扱いが必要となったときには, 表面化学 の領域の文献 ${ }^{14 \sim 17)}$ から目的に合う等温式を探 すことが, 膜工学では役立つであろう.

\section{3. 二元収着モデル}

ガラス状高分子への気体の溶解度があまり高く ないとき, $\mathrm{p}$ が低い領域で $\mathrm{p}$ 軸に凹, $\mathrm{p}$ の増加とと もに直線に近づいていき, 高圧領域では完全に直
線となる収着等温線が観察されることが多い。こ の形の等温線は, Barrer ら ${ }^{18)}$ および Michaels ら ${ }^{19)}$ の提案した二元収着モデルによってよく説 明できる.このモデルでは, ある圧力 $\mathrm{p}$ のも に高分子固体に収着した気体の量 C は, Henry の法則に従う量 $\mathrm{C}_{D}$ と, Langmuir の吸着理論に 従う量 $\mathrm{C}_{H}$ との和であるとする。 $\mathrm{C}_{D}$ によって表 される収着モードに関与する機構は, 有機低分子 液体への気体の溶解機構と同じであろうと考えら れ，一方 $\mathrm{C}_{H}$ によって表されるモードは，ガラス 状高分子固体中に多数存在している空孔, ミクロ ボイドへの気体分子の吸着と想像されている.す なわち収着等温線は

$$
\begin{aligned}
\mathrm{C} & =\mathrm{C}_{D}+\mathrm{C}_{H} \\
& =\mathrm{k}_{D} \mathrm{p}+\mathrm{C}_{H}{ }^{\prime} \mathrm{bp} /(1+\mathrm{bp})
\end{aligned}
$$

によって表される.ここで $\mathrm{k}_{D}$ は Henry 則定数, $\mathrm{C}_{H}{ }^{\prime}, \mathrm{b}$ はそれぞれ Langmuir 定数, 親和力定数 と呼ばれるパラメーターである ${ }^{20)}$. 二元収着モ デルは多くの気体一ガラス状高分子系の収着挙動 をよく説明し, 結果の解析や考察に用いられるだ けでなく，挙動の予測にも役立っている20 24). さらにこのモデルは, 高分子膜を通っての低分子 の透過にも拡張され，この二元輸送 (移動度) モ デルも多くの系の挙動の解析や予測に成功してい $\tau^{20 \sim 24)}$, 気体・蒸気の膜透過, あるいは気体 分離の工学に関しては最も優れたモデルの 1 つで あると言っても過言ではない．しかし膜科学の立 場からすると，考慮すべき問題点がいくつかある ように思われる.

まず問題となるのは, Frisch, Stern が指摘し

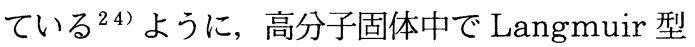
収着が起こるとされている場所に対して, 空孔, ミクロボイド,あるいは高分子鎖間のギャップと, いろいろな表現が用いられていて，この収着モー ドの分子レベルでの像が一向に明らかでないこと である.もしこの空孔などと呼ばれているものの 大きさが, ガラス状高分子固体中に存在する, 電 子顕微鏡で観察することのできない, 分子レベル あるいはこれに近いレベルの大きさであるとする と,この空孔の壁への気体分子の吸着を考えたと 


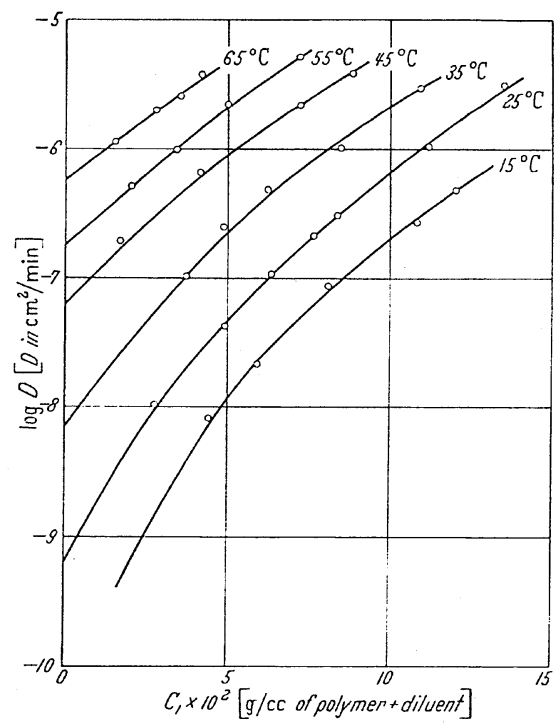

Fig. 3 Plots of diffusion coefficient against penetrant concentration for sorption of ethyl acetate in poly(methyl acrylate) at different temperatures ${ }^{32)}$.

き，その環境は Langmuir 理論の誘導で考えら れた環境4)とはあまりにも違いすぎる。したがっ て, パラメーター $\mathrm{C}_{H}$ にについての議論は定性的 には認められても, b に関する考察は全く異なる 立場よりしなければならない，ちなみに，その理 由は推察できないが, 膜科学に関する多くの論文 では, 考察は専ら $\mathrm{C}_{H}$ にについてのものに限られ ており, b に関する議論はわずかしか見受けられ ない.

次に挙げられる問題点は, 高分子固体に収着し た低分子に，二元収着モデルで考えられているよ

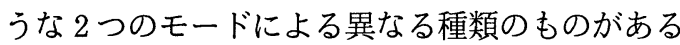
ことが, 収着測定とは全く別の実験によって, た だ 1 つの古い報告 ${ }^{25)}$ を除いては，いまだに実証 されていないということである. 最近のポリカー ボネート, ポリスチレンへの ${ }^{13} \mathrm{CO}_{2}$ 収着の $\mathrm{NMR}$ 研究からは, 2 種類の収着低分子の存在に対する 決定的証拠は得られていない26.27). また, $\mathrm{CO}_{2}$ を収着したポリメタクリル酸メチルなどのガラス 状高分子固体についての, 赤外分光法による最近 の研究も, 二元収着モデルの, 2 種類の収着低分
子が存在するという基本的仮定に対して否定的な 結果を与えている28).

3 番目の問題点として, パラメーター $\mathrm{C}_{H}{ }^{\prime}$ と収 着気体分子の Lennard-Jones の力の定数の間の 関係がある. $\mathrm{C}_{H}$ ' の対数と力の定数の関係は直線 で表されるが, Langmuir の理論からは, パラ メーター b についてこのような依存性が考えら れても, $\mathrm{C}_{H}$ にについては期待されない21)。

以上述べてきたように, 膜科学の分野では二元 収着モデルを分子論的なモデルと見るにはいくつ かの疑問がある. すなわち, 高分子物理化学のモ デルとして二元収着モデルを見ると, 現象論的な 面が非常に強いモデルであって，このモデルを用 いた解析の結果に基づいて, 分子レベルでの詳細 な議論を展開することは適当ではない.

\section{Fick 型過程}

ゴム状高分子膜への気体・蒸気の動的な収着の 過程, あるいは吸収過程, および脱着の過程は, Fick 型である $22 \sim 24,29.30)$. すなわち, 収着量 を時間の平方根に対してとった，いわゆるフィッ キアンプロットは, 初期から平衡収着量の半分以 上に達する領域にわたって直線が続き, その後変 曲点が現れず，時間軸に対して凹となって平衡に 達する. 脱着のフィッキアンプロットも同様な形 である.このような収着過程の特徴は, 数学的モ デルによって表現できる22 24,29 31).

Fick 型の収着・脱着過程を解析して, 一定, あるいは濃度の関数としての拡散係数を求める方 法は確立している22 24,29 31). 収着・脱着過 程が上に示した特徴をもっていない非 Fick 型の 場合には, 一般に収着・脱着過程の解析から拡散 係数を評価することはできない. 有機蒸気一ゴム 状高分子系の拡散係数は低分子濃度とともに増加 し, 酸素などの単純気体あるいは水蒸気との系で は拡散係数は濃度に依存しない場合が多い. 前者 の系の典型的な例を Fig. $3^{32)}$ に示す. 図から明 らかなように, 拡散係数は温度が高くなるととも に大きくなる. 


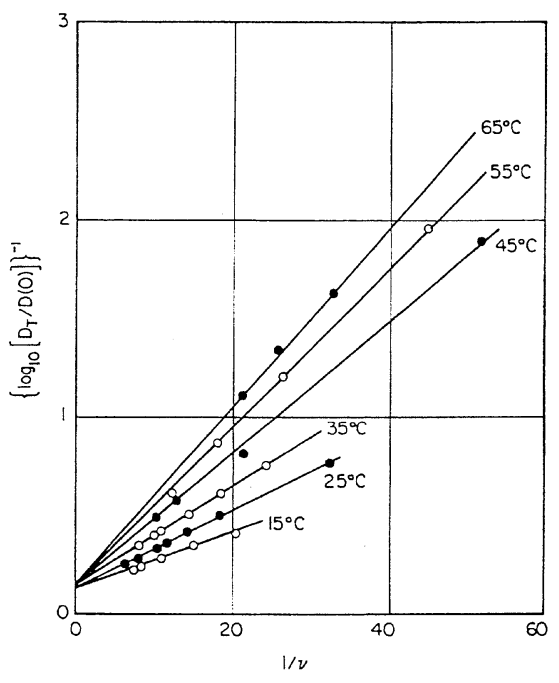

Fig. 4 Fujita plots for sorption of ethyl acetate in poly (methyl acrylate).

$\mathrm{D}_{\mathrm{T}}$ is the thermodynamic diffusion coefficient ; $\mathrm{D}(0)$ is the value of $\mathrm{D}_{\mathrm{T}}$ in the zero concentration limit ; and $\mathrm{v}$ is the volume fraction of ethyl acetate $^{32)}$.

\section{5. 自由体積モデル}

前節に述べた低分子一高分子系の拡散係数の濃 度や温度への依存性は, 自由体積モデルによって よく説明することができる. 自由体積は，もとも 之, 剛体球モデルや擬結晶モデルでは説明が難し かった，低分子液体の流動性を説明するために導 入された概念であるから，これを高分子を含む系 に用いることができるのは，系がゴム状態にある ときに限られる．ゴム状高分子について，ある温 度で, 測定された体積と高分子を構成する原子, 原子団の占有体積との差を, 自由体積と定義する のが，最も一般的な定義である．ゴム状態では自 由体積分率は温度とともに増加し，これに基づい て拡散係数の温度依存性が説明される. 低分子お よび高分子物質の流動を扱うレオロジーの分野, すなわち動的物性を対象とする分野では，系のガ ラス転移温度以下の状態では，自由体積分率は一 定であると認識されている（ガラス転移に対する 等自由体積理論).したがって，ガラス状態のあ る温度で, 未緩和体積と呼ばれている, 測定され
た体積と占有体積の差を自由体積と呼ぶことは, 高分子物性の関係する議論では，いたずらに混乱 を生むだけである。

高分子固体に収着された低分子は，高分子に比 べて大きい自由体積をもっているものと考えられ る. したがって高分子への気体・蒸気の収着が起 こると, 系の自由体積は収着量に比例して増加す る. 藤田 ${ }^{29.30)}$ および Vrentas, Duda ${ }^{10}$. 33) の 自由体積モデルは, このことに基づいて展開され たものである．藤田のモデルは，Fig. $4^{32)}$ に示 したように, Fig. 3 の測定結果を非常によく説明 する. Fig. 4 で, 丸印が測定結果から藤田モデル により計算した，いわゆる藤田プロットである. 藤田モデルでは自由体積分率は, Vrentas, Duda モデルのように高分子の占有体積の值などを 用いて定められているのではなく, 移動度と関係 させて，いわば動的な定義がされている。このた めに藤田モデルは, 自由体積に対して明確な物理 的イメージを描くことが難しく，またVrentas， Duda モデルのように, 拡散係数とその濃度依存 性を予測することができないという欠点をも $\supset^{34)}$. 一方, Vrentas, Duda モデルは, 低分子 成分のガラス転移温度のデータが必要なので, 適 用できる系が有機低分子と高分子の系に限られ， 膜分離工学で関心が高い, 気体と高分子の系には 使えない，収着過程を藤田モデルで解析して得ら れた自由体積パラメーターの值は，高分子溶液の 粘度一濃度関係のような, レオロジ一測定の結果 から導いた値とよく一致する ${ }^{29)}$.

\section{6. おわりに}

気体・蒸気と高分子の系の平衡的および動的収 着挙動，あるいはこれらが複合した膜透過挙動の シミュレーション，予測ができるということは， 膜工学における取扱いでは必ず満たさなければな らない条件である。この意味では, 平衡収着特性 に関して, Langmuir 等温式だけでなく，他の 2 および 3 パラメーター等温式が, 測定結果の数量 的表現も含めてもっ之利用されてもよいのではな いかと思われる．動的な収着特性については，い 
膜 (MEMBRANE), Vol. 21 No. 6 (1996)

361

ろいろな気体・蒸気一高分子系について, 拡散係 数の濃度・温度依存性の予測となると, 可能な系 は現在ではごくわずかなものに限られていて, 膜 透過特性への展開も視野に入れた, 使いやすいモ デル, 取扱いの出現が待たれる. 膜科学の分野で は, 現在デー夕解析に用いられている半現象論的 モデルのパラメーターと, 低分子あるいは高分子 の分子特性との関連については, かなりの結果が 集積されてきている. しかし残念なことに, 解析 の結果から分子レベルでの議論が十分にできるモ デルはまだ現れてはいない. 分子膜科学への道は まだ近くはなさそうである.

\section{文 献}

1) IUPAC Phys. Chem. Div. : Pure Appl. Chem., 57, 603-619 (1985)

2) IUPAC Macromol. Div. : Pure Appl. Chem., 68, 1479-1489 (1996)

3）小谷 壽: 「高分子と水」, 高分子学会編, p. 1-26, 共立出版 (1995)

4) Langmuir I. : J. Am. Chem. Soc., 40, 13611403 (1918)

5) Brunauer S., Emmett P. H., Teller E. : $J$. Am. Chem. Soc., 60, 309-319 (1938)

6) Jura G., Harkins W. D. : J. Chem. Phys., 11, 430-431 (1943)

7）例えば, 千原秀昭, 中村亘男訳 : 「アトキンス物理 化学 (下) 第 4 版」, 29 章, 東京化学同人 (1993)

8) Halsey J. : J. Chem. Phys., 16, 931-937 (1948)

9）岡小天, 金丸競訳 :「フローリ, 高分子化学 下」, 12 章, 丸善 (1951)

10) Duda J. L., Vrentas J. S., Ju S. T., Liu H. T. : AIChE J., 28, 279-285 (1982)

11) Odani H., Masuda T. : "Polymers for Gas Separation", Toshima N. Ed., Chap. 4, VCH Publishers, New York (1992)

12) Nakanishi K., Odani H., Kurata M., Masuda T.,Higashimura T. : Polym. J ., 19, 293-296 (1987)

13) Fowler R. H. : Proc. Camb. Phil. Soc., 32, 144 (1936)

14) Brunauer S. : "The Adsorption of Gases and Vapors, Vol. I Physical Adsorption”, Oxford Univ. Press, Oxford (1945)

15) Young D. M., Crowell A. D. : "Physical Adsorption of Gases", Butterworths, London
(1962)

16) Somorjai S. : "Principles of Surface Chemistry”, Prentice-Hall, Englewood Cliffs, N. J. (1972)

17) Adamson A. W. : "Physical Chemistry of Surfaces,Fourth Ed.”, John Wiley \& Sons, N.Y. (1982)

18) Barrer R. M., Barrie J. A., Slater J. : J. Polym. Sci., 27, 177-197 (1958)

19) Michaels A. S., Vieth W. R., Barrie J. A. : J. Appl. Phys., 34, 1-12 (1963)

20) Stannett V. T., Koros W. J., Paul D. R., Lonsdale H. K., Baker R. W. : Adv. Polym. Sci., 32, 69-121 (1979)

21) Petropoulos J. H. : Adv. Polym. Sci., 64, 93142 (1985)

22) Rogers C. E. : "Polymer Permeability", J. Comyn Ed., Chap. 2, Elsevier Appl. Sci. Pub., London (1985)

23) W. R. Vieth: "Diffusion In and Through Polymers”, Chap. 2, Hanser Pub., Munich (1991)

24) Frisch H. L., Stern S. A. : Crit. Rev. Solid State Mater. Sci., 11, (2) 123-187 (1983)

25) Assink R. A. : J. Polym. Sci. Polym. Phys. Ed., 13, 1665-1673 (1975)

26) Cain E. J., Wen W. -Y., Jones A. A., Inglefield P. T., Cauley B. J., Bendler J. T. : J. Polym. Sci. : Part B : Polym. Phys., 29, 10091020 (1991)

27) Bandis A., Cauley B. J., Inglefield C. E., Wen W. -Y., Inglefield P. T., Jones A. A., Melc'uk A., J. Polym. Sci. : Part B : Polym. Phys., 31, 447-453 (1993)

28) Higuchi A., Nakagawa T., J. Polym. Sci. : Part B : Polym. Phys., 32, 149 (1994)

29) Fujita H. : Fortschr. Hochpolym. -Forsch., 3, 1-47 (1961)

30) Fujita H. : “Diffusion in Polymers”, J. Crank, G. S. Park Eds., Chap. 8, Academic Press, London (1968)

31）戸井啓雄 :「高分子と水」, 高分子学会編, p. 27-50, 共立出版 (1995)

32) Fujita H., Kishimoto A., Matsumoto K. : Trans. Faraday Soc., 56, 424-437 (1960)

33) Vrentas J. S., Duda J. L. : J. Polym. Sci. : Polym. Phys. Ed. : 15, 403-416 (1977)

34) Fujita H. : Chem. Eng. Sci., 48, 3037-3042 (1993)

（受付 1996 年 9 月 7 日 掲載决定 9 月 22 日） 